\title{
Psychometric Evaluation of the Chinese Version of the Patient Perceptions of Empowerment Scale (PPES)
}

\author{
Mei-Yu Yeh, ${ }^{1}$ Sieh-Hwa Lin, ${ }^{2}$ and Tao-Hsin Tung ${ }^{3,4}$ \\ ${ }^{1}$ Graduate Institute of Health Care, Chang Gung University of Science and Technology, Taoyuan 33303, Taiwan \\ ${ }^{2}$ Department of Educational Psychology and Counseling, National Taiwan Normal University, Taipei 10610, Taiwan \\ ${ }^{3}$ Department of Public Health, School of Medicine, Fu-Jen Catholic University, Taipei 24205, Taiwan \\ ${ }^{4}$ Department of Medical Research and Education, Cheng-Hsin General Hospital, Taipei 11220, Taiwan
}

Correspondence should be addressed to Tao-Hsin Tung; ch2876@gmail.com

Received 7 January 2014; Revised 28 April 2014; Accepted 1 May 2014; Published 29 May 2014

Academic Editor: Nick Kontodimopoulos

Copyright (C) 2014 Mei-Yu Yeh et al. This is an open access article distributed under the Creative Commons Attribution License, which permits unrestricted use, distribution, and reproduction in any medium, provided the original work is properly cited.

Objectives. To evaluate the psychometric properties of the Chinese version of the Patient Perceptions of Empowerment Scale (PPES) and to perform a cross-cultural validity assessment. Methods. In this cross-sectional survey, 554 inpatients in three general hospitals in northern Taiwan were recruited. Principal component analysis was used to examine the factor structure of the scale. Confirmatory factor analyses were conducted on the measurement model of the Chinese version of the PPES. Results. Confirmatory factor analyses supported the presence of a second-order four-factor model (information, decision, individual, and self-management) of the Chinese version of the PPES when used with a Taiwanese inpatient population. The results indicate that the 11-item, second-order, four-factor Chinese version of the PPES provided best goodness-of-fit for the data in this study. Conclusion. The 11-item four-factor Chinese version of the PPES is a self-completion scale. This study demonstrated that the Chinese version of the PPES is a reliable and valid self-report instrument for the assessment of patient perceptions of empowerment in clinical practice. Further adaptation and evaluation of the scale will hopefully stimulate further studies on PPES in the fields of psychometrics in Taiwan.

\section{Introduction}

The term "empowerment" comes from the Latin verb for power, "potere," which means "to be able." Its prefix, "em," means "cause to be" or "provide with" [1]. The Oxford English Dictionary defines empowerment as "to give someone the power to do something; to make someone more confident, especially in controlling their life and claiming rights" [2]. Hence, empowerment means to give power to (empower) or to make able (enable) [3].

From the evidence-based viewpoint, empowerment is a process of awareness, enabling involved individuals to assert control over the problems that affect their health, thus achieving self-determination. Within an empowerment framework, the responsibility of health-care providers is to recognize the suffering of patients, identify patients' strengths, and prevent further marginalization of patients due to power inequality $[4,5]$. In the empowerment process, the patient has the right to choose their treatment. Health care providers provide clear, concise, accurate information [6] and patients can access and discuss a range of information, options, and views to help them self-determine and self-manage their disease $[3,7]$. The concept of patient empowerment emphasizes health care to be patient-centered, providing educational materials and decision-making aids, such as leaflets, computer programs, interactive videos, websites, and group presentations [8]. These materials help patients identify their own skills and needs and empower themselves instead of just focusing on compliance with the offered treatments $[7,8]$.

The concept of patient empowerment is complex and multidimensional and is a construct applicable to individuals, communities, and organizations $[9,10]$.

The Patient Perceptions of Empowerment Scale (PPES) was used to investigate coronary-care inpatients' perceptions of interventions related to patient choice, and to identify the patient empowerment benchmarks within clinical practice. 
TABLE 1: Summarized research results of empowerment scale.

\begin{tabular}{|c|c|c|c|c|}
\hline Author(s) & Measure & Methods & Subjects & Results \\
\hline Lewin and Piper [11] & $\begin{array}{l}\text { 17-item } \\
\text { patient perceptions of } \\
\text { empowerment scale }\end{array}$ & Frequency score and rank & 142 inpatients & $\begin{array}{l}\text { The } 17 \text { items were rescored on a } \\
\text { five-point scale; the higher score, } \\
\text { the more satisfied the respondent }\end{array}$ \\
\hline $\begin{array}{l}\text { Anderson et al. } \\
{[12,13]}\end{array}$ & $\begin{array}{l}\text { 28-item diabetes-patient } \\
\text { empowerment scale }\end{array}$ & $\begin{array}{l}\text { Principal component } \\
\text { analysis }\end{array}$ & $\begin{array}{l}375 \text { and } 229 \text { diabetes } \\
\text { patients }\end{array}$ & $\begin{array}{l}\text { Three-factor solution accounts } \\
\text { for } 56 \% \text { of the total variance }\end{array}$ \\
\hline Bulsara et al. [14] & $\begin{array}{l}\text { 28-item patient } \\
\text { empowerment scale }\end{array}$ & Rasch model analysis & 100 cancer patients & $\begin{array}{l}\text { Fitted the Rasch model with the } \\
\text { exception of } 2 \text { items }\end{array}$ \\
\hline Faulkner [15] & $\begin{array}{l}\text { 100-item patient- } \\
\text { empower- } \\
\text { ment/disempowerment } \\
\text { scale (frequency-of- } \\
\text { action scale) }\end{array}$ & Frequency score & 102 elderly patients & $\begin{array}{l}\text { Offered as a means of identifying } \\
\text { hospital environments which } \\
\text { facilitate independence }\end{array}$ \\
\hline Chen et al. [16] & $\begin{array}{l}15 \text {-item diabetes-patient } \\
\text { empowerment process } \\
\text { scale }\end{array}$ & $\begin{array}{l}\text { Principal component- } \\
\text { and confirmatory factor } \\
\text { analysis }\end{array}$ & 211 diabetes patients & $\begin{array}{l}\text { Second-order four-factor model; } \\
\text { four factors: raising awareness, } \\
\text { mutual participation, providing } \\
\text { information, and communication }\end{array}$ \\
\hline $\begin{array}{l}\text { Hansson and } \\
\text { Björkman [17] }\end{array}$ & $\begin{array}{l}\text { 28-item empowerment } \\
\text { scale }\end{array}$ & $\begin{array}{l}\text { Confirmatory factor } \\
\text { analysis }\end{array}$ & $\begin{array}{l}176 \text { subjects with mental } \\
\text { illness }\end{array}$ & $\begin{array}{l}\text { Good construct validity; } \\
\text { two-factors: self-esteem and } \\
\text { activism and community and } \\
\text { power }\end{array}$ \\
\hline Kettunen et al. [18] & $\begin{array}{l}\text { 43-item } \\
\text { empowering-speech } \\
\text { scale }\end{array}$ & $\begin{array}{l}\text { Confirmatory factor } \\
\text { analysis }\end{array}$ & 127 counseling situations & $\begin{array}{l}\text { Second-order two-factor solution } \\
\text { explained } 59 \% \text { of variation }\end{array}$ \\
\hline Rogers et al. [19] & $\begin{array}{l}\text { 28-item empowerment } \\
\text { scale }\end{array}$ & $\begin{array}{l}\text { Principal components } \\
\text { factor analysis }\end{array}$ & $\begin{array}{l}271 \text { members of six } \\
\text { self-help Programs }\end{array}$ & $\begin{array}{l}\text { Five-factors: self-efficacy, power, } \\
\text { community activism; righteous } \\
\text { anger; and optimism and control } \\
\text { over the future }\end{array}$ \\
\hline
\end{tabular}

It also was linked to concepts of self-care, personal control, and demonstrating the ability, confidence, and insight to enhance the individual's well-being [11]. In addition, the psychometric properties of PPES includes 5 factors: giving of information about treatment and care, having a voice in the choice and direction of clinical management, getting an informed consent by the patient prior to treatment, providing individualized care, respecting the patient as an individual, and self-management of diseases with knowledge and confidence [11]. Although a number of empowerment (and other) scales are presented (Table 1) [11-19], only PPES could be used in clinical research to predict inpatient empowerment and to evaluate patient-education outcomes. The objective of this study was to examine the psychometric properties of the Chinese version of the PPES and to perform a cross-cultural validity assessment.

\section{Methods}

2.1. Participants. The survey was conducted in three general hospitals in Taiwan from January to July 2009. We excluded patients in pediatrics, psychiatry, and intensive care for difficulty of collecting accurate data. We recruited 554 patients who were able to express willingness in either Mandarin or Taiwanese and who had been hospitalized for three or more days in internal medicine, surgery, gynecology, neurology, or one or more of the 18 other wards. A total of 554 inpatients met these inclusion criteria and comprised the study sample.
All participants completed a questionnaire pack at one time point.

2.2. Ethical Considerations and Procedures. The institutional review boards at three hospitals approved this study in 2008. The research procedures and recruiting criteria were explained to nurses before they contacted potential subjects. All participants were referred by nurses and gave informed consent for participation in this study. It was emphasized that participation was voluntary and could be withdrawn at any time, and subjects' responses were to be considered anonymous and confidential. The researchers explained the risks and benefits of participation, and the patients' right to refuse to participate without jeopardizing treatment. Participants were given verbal and written explanations of the study's purpose and design. Methods and procedures of data collection, use and analysis, and storage were explained. Research data was then collected using a self-report questionnaire, in which the patients were required to complete within 20 minutes.

\subsection{Instruments}

2.3.1. The Original Patient Perceptions of Empowerment Scale (PPES). The original version of the PPES contains 17 items and uses a five-point Likert scale, which ranged from strongly agree to strongly disagree. The factors of the PPES are as follows: giving of information about treatment and care; having 
a voice in the choice and direction of clinical management; getting an informed consent by the patient prior to treatment; providing individualized care and respecting the patient as an individual; and self-management of diseases with knowledge and confidence [11].

The Chinese version of the PPES was created using the back-translation method. First, the original version was translated into Chinese by a professional translator. The first author then back-translated the Chinese version, and the result was compared with the original English version to ensure that the words chosen in the translation carried their original connotations.

Content validity is used to assess the relevance and the comprehensiveness of the items. Before conducting our preliminary research, five nursing experts based on their clinical professions and experiences examined the content validity; that is, when experts were asked whether they missed items this could be considered as an indication that the comprehensiveness of the items was assessed. The five experts included a clinical specialist, two nursing supervisors, and two assistant professors. In order to avoid that the particular composition of participants may bias towards certain subdimensions of the scale, convergent validity and discriminant validity are assessed through confirmatory factor analyses (CFA). In addition, the information regarding the construct reliability (composite reliability, a measure of the overall reliability of a collection of heterogeneous but similar items) and construct validity (the degree to which the performance of the items on a translated or culturally adapted PPES instrument is adequate reflection of the performance of the items of the original version of the PPES instrument) of the scale was considered to test the psychometric properties of the PPES in this study.

2.3.2. The Patient Satisfaction Questionnaire (PSQ). The PSQ has frequently been used as a measurement of quality of nursing care, especially in attempts to demonstrate the patients' experiences during and post of treatment. The PSQ includes 11 questions on a Likert scale [20]. The PSQ range of total scores is 11-55, with higher scores indicating higher degrees of satisfaction with nursing care. The internal consistency of the scale was estimated using Cronbach's alpha coefficients. The coefficients of internal consistency greater than 0.80 or 0.90 are considered as very good or excellent [21]. In our pilot study, the PSQ total-scale Cronbach's alpha coefficient was 0.91 .

2.3.3. Sufficiency of Patient Education Questionnaire (SPEQ). The SPEQ has been used to evaluate whether the education patients received was sufficient within the hospitalization period. The SPEQ includes 8 items on a Likert scale. The range of total scores is $8-40$, with lower scores indicating lesssufficient patient education within the hospitalization period [22]. In our pilot study, the Cronbach's alpha coefficient of SPEQ was 0.92 .

2.4. Statistical Analysis. SPSS version 20.0 for Windows was used to perform descriptive statistics, Pearson correlation, and exploratory factor analysis (EFA). The dimensionality of the scale was evaluated by EFA, using Kaiser's criterion (eigenvalue $\geq 1$ ), estimated by the maximum-likelihood method and rotated with the varimax method [21]. CFA were also conducted using the second-order four-factor measurement model of the PPES based on results of EFA. These analyses were performed using the structural-equation modeling (SEM) statistics package LISREL 8.80.

The goodness-of-fit of the models was estimated using the covariance matrix as input and a maximum-likelihood solution [23, 24]. The LISREL software program was used to examine the parameter, test the hypothesis model, and estimate the population covariance matrix generated by this model $[25,26]$. Browne and Cudeck [27] indicated that there were multiple goodness-of-fit indices to provide information on how well the model fits the data. Using structural-equation modeling, several model-fit indices were evaluated: the Root Mean Square Error of Approximation (RMSEA), Incremental Fit Index (IFI), Comparative Fit Index (CFI), Nonnormed Fit Index (NNFI), Goodness of Fit Index (GFI), and Standardized Root Mean Square Residual (SRMR). RMSEA values smaller than 0.10 indicate a good fit, with values below 0.05 indicating a very good fit. CFI, GFI, IFI, and NNFI values greater than 0.90 indicate a good-fit $[24,25,28]$. SRMR values less than 0.05 are interpreted as indicating a good fit to the data [23]. In addition, construct validity was used to explore the expected correlations between PPES and PSQ and between PPES and SPEQ. The construct validity of the PPES was assessed by second-order factor analyses [29]. The purpose of the second-order factor analysis is to explore how strongly the first-order factors load on the hypothesized second-order factor, that is, to estimate to what extent the explained factors of meaning, competence, selfdetermination, and impact could be accounted for by the more generic concept of PPSE [21]. The second-order factor analysis also could be used to study construct validity because it assesses the degree to which some items load on a certain hypothesized first-order factor and at the same time load very insignificantly on other first-order factors [21]. Finally, we examined raw scores and Pearson's correlation coefficients; the correlations were performed using the SPEQ and PSQ to assess the concurrent validity.

\section{Results}

The content validity index (CVI) for the PPES was 0.93. As recommended by these experts; we removed two questions which did not reflect clinical practice in Taiwanese hospitals; the 9th and 13th items were removed. The second draft of the PPES, at this point containing 15 items, was evaluated for item clarity by 20 inpatients. The 8 th and 16 th items were regarded as socially and culturally inapplicable and, therefore, deleted, leaving 13 items.

In the pilot study, we collected data from 30 inpatients to examine internal consistency. The 13-item PPES totalscale reliability coefficient was 0.86 . Item analyses were then used to examine how each item correlated with the total score. Items with item-to-total correlations lower than 0.3 
TABLE 2: Results of exploratory factor analysis (EFA) of the PPES using principal component analysis with varimax rotation $(n=554)$.

\begin{tabular}{|c|c|c|c|c|}
\hline \multirow{2}{*}{ PPES items } & \multicolumn{4}{|c|}{ Factor loading } \\
\hline & Factor 1 & Factor 2 & Factor 3 & Factor 4 \\
\hline Item 1 & 0.82 & & & \\
\hline Item 2 & 0.83 & & & \\
\hline Item 3 & 0.84 & & & \\
\hline Item 6 & & & 0.79 & \\
\hline Item 7 & & & 0.85 & \\
\hline Item 10 & & 0.88 & & \\
\hline Item 11 & & 0.88 & & \\
\hline Item 12 & & 0.67 & & \\
\hline Item 14 & & & & 0.58 \\
\hline Item 15 & & & & 0.80 \\
\hline Item 17 & & & & 0.74 \\
\hline$\%$ of variance & 45.62 & 9.52 & 8.41 & 7.03 \\
\hline Cumulative variance & 45.62 & 55.14 & 63.55 & 70.57 \\
\hline Cronbach's $\alpha$ of subscale & 0.81 & 0.77 & 0.67 & 0.63 \\
\hline
\end{tabular}

were deleted, because they did not sufficiently contribute to measuring the concept and reduced the scale's homogeneity [20]. At this stage, we deleted the 4 th $(r=-0.15)$ and 5 th $(r=-0.08)$ items. The final 11-item version of the PPES was used for the rest of this study.

A total of 554 inpatients participated in this study, in which 291 (52.5\%) were male and 263 (47.5\%) were female. Ages of the participants ranged from 20-99 years (mean age $=$ 52.75). Participants had an average of 9.94 years of education and $9.9 \%$ had not been employed recently.

Using principal component analysis, the researchers analyzed the construct validity of the Chinese version of the PPES by using varimax rotation to extract four factors (Table 2). The exploratory factor analysis was performed in order to be able to directly inspect whether or not the factor-loading matrix possessed the so-called simple structure. The four extracted factors explained $70.57 \%$ of the total variances. The factor loadings of the 11 questions were between 0.58 and 0.88 , the Kaiser-Meyer-Olkin (KMO) measure of sampling adequacy was 0.888 , and the Bartlett test of sphericity was $2484.266(\mathrm{df}=55 ; P<0.001)$. The four factors were named "information" (three items), "decision" (two items), "individual" (three items), and "self-Management" (three items). The Cronbach's alpha values of the four subscales (four factors) were between 0.63 and 0.81 .

All standardized factor loadings of items were significant ( $t$ value larger than 2 ), with factor loadings ranging from 0.68 to 0.84 for the information factor, 0.65 to 0.78 for the decision factor, 0.55 to 0.90 for the individual factor, and 0.55 to 0.71 for the self-management factor. Total cumulative variances ranged from 0.62 to 0.77 in the four-factors (Table 3 ). These results indicate good convergent validity $[28,30]$. Bagozzi and $\mathrm{Yi}$ indicated that a construct reliability (composite reliability) higher than 0.60 and total cumulative variances greater than 0.50 are acceptable [31]. In the present study, the construct reliability was 0.93 for information, 0.80 for decision, 0.93 for individual, and 0.84 for self-management (Table 3). These findings support the second-order four- factor model proposed by exploratory factor analysis and the construct validity of the PPES.

The goodness-of-fit analysis revealed $\chi 2=122.37, \mathrm{df}=$ $40, P<0.001, \mathrm{NC}=3.05, \mathrm{CN}=281.15, \mathrm{RMSEA}=$ 0.061 , IFI $=0.98, \mathrm{CFI}=0.98, \mathrm{NNFI}=0.98$, GFI $=0.96$, and SRMR $=0.045$. These results clearly indicate that the second-order four-factor model has a reasonable degree of approximation for this population and is acceptable for use in research and clinical applications (Table 4).

Significant correlation coefficients were $0.68(P<0.01)$ for the SPEQ and $0.64(P<0.01)$ for the PSQ, providing concurrent evidence for validity. The significant correlation coefficients for individual factors within SPEQ were 0.60 $(P<0.01)$ for information, $0.59(P<0.01)$ for decision, $0.55(P<0.01)$ for individual, and $0.47(P<0.01)$ for self-management (Table 4 ). These results indicate that the more sufficient patient education is, the more empowered the individual is likely to control or self-manage their problem. The correlation value was in the expected direction and supported the concurrent validity of the SPEQ and PSQ.

\section{Discussion}

4.1. Discussion. In the present study, the four-factor model of the Chinese version of the PPES was simplified to 11 items. Each factor has two to three questions in which adequate convergent validity is all embodied. Confirmatory factor analyses provided moderate support for the 11-item fourfactor model of the PPES. Therefore, this second-order fourfactor solution of the Chinese version of the PPES is a bestfit model verified for use in Taiwan $[28,30]$. In terms of the concepts of PPES, four-factor was also related to perceived patient satisfaction and linked with the concepts of self-care, self-responsibility, and personal control [11]. Piper indicated the nurse as an empowerment facilitator that focuses on patient-defined needs, making sure patients are fully aware of treatment options and implications and fosters active patient participation [32]. Interventions are grounded in process 
TABLE 3: Completely standardized solution for the second-order four-factor models $(n=554)$.

\begin{tabular}{|c|c|c|c|}
\hline Variables & Estimates & $\begin{array}{l}\text { Construct } \\
\text { reliability }\end{array}$ & $\begin{array}{c}\text { Totally cumulative } \\
\text { variances }\end{array}$ \\
\hline Information & 0.88 & 0.93 & 0.77 \\
\hline (1) The staff gave me clear information on how best to manage my illness. & 0.84 & & \\
\hline (2) Overall, I felt that I was talked at by the staff rather than listened to. & 0.79 & & \\
\hline (3) I wish I could have had more say in my treatment and care. & 0.68 & & \\
\hline Decision & 0.89 & 0.80 & 0.72 \\
\hline (6) I felt that I always gave my consent before a clinical procedure was carried out. & 0.78 & & \\
\hline (7) I always felt that the purpose of my prescribed medication was fully explained. & 0.65 & & \\
\hline Individual & 0.75 & 0.93 & 0.76 \\
\hline (10) The staff did everything possible to help me with anxieties over my illness. & 0.84 & & \\
\hline (11) The staff was always helpful and understanding over visiting times. & 0.90 & & \\
\hline (12) I felt that I was being treated as an individual by all members of staff. & 0.55 & & \\
\hline Self-management & 0.84 & 0.84 & 0.62 \\
\hline (14) I had to ask for advice about what I should and should not do on discharge. & 0.59 & & \\
\hline (15) At no time did I feel that the truth about my condition was being hidden from me. & 0.55 & & \\
\hline (17) From time to time the staff gave me contradictory advice about my condition. & 0.71 & & \\
\hline
\end{tabular}

* Estimate value greater than 0.50 , construct reliability greater than 0.60 , and totally cumulative variances higher than 0.50 were acceptable.

TABLE 4: Fit indices for the four-factor models and correlation between SPEQ and PSQ $(n=554)$.

\begin{tabular}{lcc}
\hline Fit indices & Fit criteria & Four-factor model \\
\hline Model $\chi^{2}(\mathrm{df})$ & - & $122.37(40)$ \\
$P$ & - & $<0.001$ \\
$\chi^{2} / \mathrm{df}(\mathrm{NC})$ & $<5$ & 3.05 \\
Critical $N(\mathrm{CN})$ & $>200$ & 281.15 \\
RMSEA & $0.05-1.0$ & 0.061 \\
IFI & $>0.90$ & 0.98 \\
CFI & $>0.90$ & 0.98 \\
NNFI & $>0.90$ & 0.98 \\
GFI & $>0.90$ & 0.96 \\
AGFI & $>0.90$ & 0.94 \\
SRMR & $<0.05$ & 0.045 \\
\hline PPES four-factor & SPEQ & PSQ \\
\hline Information & $0.60^{* *}$ & $0.56^{* *}$ \\
Decision & $0.59^{* *}$ & $0.48^{* *}$ \\
Individual & $0.55^{* *}$ & $0.60^{* *}$ \\
Self-management & $0.47^{* *}$ & $0.43^{* *}$ \\
\hline PPES total score (11-item) & $0.68^{* *}$ & $0.64^{* *}$ \\
\hline$* *$
\end{tabular}

${ }^{* *} P<0.01$.

and empathy, reassurance, and support helped to develop critical awareness, confidence, self-esteem, and thus bottomup patient-led decision-making [33].

For all of the groups, the factor solutions brought about exactly four factors that justified over 70 percent of the total variance. Factor I (information) explicated most of the total variation. For both groups, the scale might be regarded as having construct validity. As Figure 1 points out, all second-order loadings $(y)$ were high (ranging from
0.55 to 0.90$)$ and all first-order loadings $(\pi)$ were also high and statistically important (varying between 0.75 and 0.89 ). In addition, Kline reported that discriminant validity refers to the distinctiveness of the factors measured by different sets of indicators [28]. If the estimated correlations of the factors that underlie sets of indicators that are supposed to measure different constructs are not excessively high, then there is evidence for discriminant validity. Although the Pearson correlation coefficient associations were slightly and moderately significant amongst the SPEQ, PSQ, and second-order four-factor model of the PPES, the significance exists and is statistically meaningful $[28,30]$. According to Kline, when correlations are examined and the $\gamma$ value is moderately significant, it can be interpreted as concurrent validity [28]. Principal component analysis and confirmatory factor analysis of the data in this study confirmed secondorder four factors within the Chinese version of the PPES.

4.2. Methodological Considerations. Several limitations should be considered when interpreting the results of this study of the Chinese version of the PPES. A very important limitation of this study is that neither stability (test retest reliability) nor responsiveness (sensitivity to change) of the Chinese PPES was assessed. Arguably, these are the key properties that would make a measure useful in the clinical context. Another major limitation to this study population is selected on a voluntary basis, which would potentially introduce selection bias. Voluntary bias can be defined as the result of the fact that a particular sample can contain only those participants who are actually willing to participate in the study and who participate and find the topic particularly interesting are more likely to volunteer for that study, same to those who are expected to be evaluated on a positive level [34]. Thirdly, this study does not present 


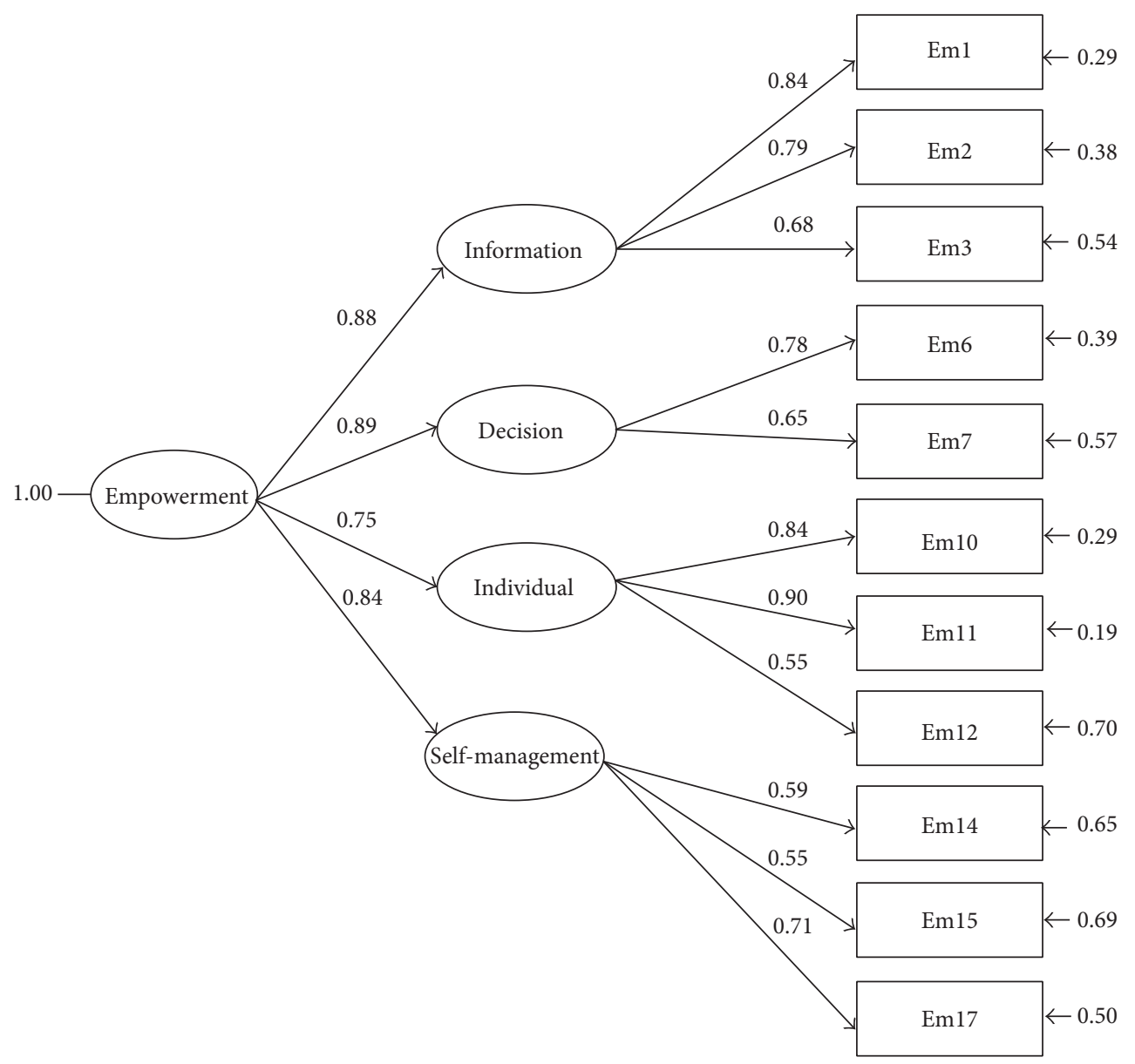

FIGURE 1: Second-order four-factor model of the PPES.

further evidence for the construct or discriminant validity of the scale. For example, the differences may occur in endorsing the underlying dimensions by participants of different age, gender, and patient characteristics. Fourthly, our measurements were conducted at only a single point in time and, by clear inference, would not only be able to be used to reflect long-term exposure to various aspects or factors, which might be important influencers of PPES, but also only internal consistency was assessed due to no demonstrated reliability of the Chinese PPES in terms of stability over time. Fifthly, published standards for translation of health measurement scales recommend 2 independent translations, review by expert panel, 2 independent back-tranlsations, and 2 nd review by expert panel [35, 36]. However, due to limited resources, the original version was translated only by a professional translator. The measurement error was inevitable. In order to ensure that the translation procedures were robust, further studies should consider conducting some cognitive interviews to ensure the Chinese wording of the items was appropriate [37]. Finally, the PPES constructs were developed by scholars in the United Kingdom considering the characteristics of the specific population studied. While the PPES was modified to fit the population in this study, future cross-cultural studies may illuminate other culturally-sensitive issues.

4.3. Practice Implications. The Chinese version of the PPES has the potential to measure and evaluate quality of healthcare related to patient-empowerment concepts. It can be used to improve the outcomes of clinical-care services in Taiwan in relation to the level of perceptions of empowerment in clinical practice. Due to the fact that stability and responsiveness of the Chinese PPES are yet to be demonstrated, further adaptation and evaluation of the scale will hopefully stimulate further studies on PPES in the fields of psychometrics in Taiwan.

4.4. Conclusions. The 11-item four-factor Chinese version of the PPES is a self-completion scale. It includes the following factors: information (three items), decision (two items), individual (three items), and self-management (three items). This study demonstrated the Chinese version of the PPES to be a reliable and valid tool for both evaluating patient-empowerment outcomes and assessing patientempowerment education in clinical and research practice. 


\section{Ethical Approval}

The Institutional Review Board approvals were obtained from three hospitals. The Chang Gung Memorial Hospital, Shin Kong Wu Ho-Su Memorial Hospital, and Landseed Hospital approved this study in November 2008; approval nos. are 971633B, 97E027, and 08-12S, respectively.

\section{Conflict of Interests}

The authors declare that there is no conflict of interests regarding the publication of this paper.

\section{Acknowledgment}

This research was supported by Taiwan National Science Council and Chang Gung Memorial hospital, Grants NSC972511-S255-002 and NMRPF 370091.

\section{References}

[1] C. Hudon, D. St-Cyr Tribble, G. Bravo, and M. E. Poitras, "Enablement in health care context: a concept analysis," Journal of Evaluation in Clinical Practice, vol. 17, no. 1, pp. 143-149, 2011.

[2] C. Sonaes and A. Sterenson, Oxford Dictionary of English, Oxford University Press, Oxford, UK, 2005.

[3] C. C. Ellis-Stoll and S. Popkess-Vawter, "A concept analysis on the process of empowerment," Advances in Nursing Science, vol. 21, no. 2, pp. 62-68, 1998.

[4] C. H. Gibson, "A concept analysis of empowerment," Journal of Advanced Nursing, vol. 16, no. 3, pp. 354-361, 1991.

[5] K. Malterud, "Power inequalities in health care-empowerment revisited," Patient Education and Counseling, vol. 79, no. 2, pp. 139-140, 2010.

[6] R. M. Anderson and M. M. Funnell, "Patient empowerment: myths and misconceptions," Patient Education and Counseling, vol. 79, no. 3, pp. 277-282, 2010.

[7] M. Christensen and J. Hewitt-Taylor, "Patient empowerment: does it still occur in the ICU?" Intensive and Critical Care Nursing, vol. 23, no. 3, pp. 156-161, 2007.

[8] I. Holmström and M. Röing, "The relation between patientcenteredness and patient empowerment: a discussion on concepts," Patient Education and Counseling, vol. 79, no. 2, pp. 167$172,2010$.

[9] H. Virtanen, H. Leino-Kilpi, and S. Salanterä, "Empowering discourse in patient education," Patient Education and Counseling, vol. 66, no. 2, pp. 140-146, 2007.

[10] R. J. Herbert, A. J. Gagnon, J. E. Rennick, and J. L. O'loughlin, “A systematic review of questionnaires measuring health-related empowerment," Research and Theory for Nursing Practice, vol. 23, no. 2, pp. 107-132, 2009.

[11] D. Lewin and S. Piper, "Patient empowerment within a coronary care unit: insights for health professionals drawn from a patient satisfaction survey," Intensive and Critical Care Nursing, vol. 23, no. 2, pp. 81-90, 2007.

[12] R. M. Anderson, M. M. Funnell, J. T. Fitzgerald, and D. G. Marrero, "The diabetes empowerment scale: a measure of psychosocial self-efficacy," Diabetes Care, vol. 23, no. 6, pp. 739$743,2000$.
[13] R. M. Anderson, J. T. Fitzgerald, L. D. Gruppen, M. M. Funnell, and M. S. Oh, "The diabetes empowerment scale-short form (DEST-SF)," Diabetes Care, vol. 26, no. 5, pp. 1641-1642, 2003.

[14] C. Bulsara, I. Styles, A. M. Ward, and M. Bulsara, "The psychometrics of developing the patient empowerment scale," Journal of Psychosocial Oncology, vol. 24, no. 2, pp. 1-16, 2006.

[15] M. Faulkner, "A measure of patient empowerment in hospital environments catering for older people," Journal of Advanced Nursing, vol. 34, no. 5, pp. 676-686, 2001.

[16] M. F. Chen, R. H. Wang, C. P. Cheng et al., "Diabetes empowerment process scale: development and psychometric testing of the Chinese version," Journal of Advanced Nursing, vol. 67, no. 1, pp. 204-214, 2011.

[17] L. Hansson and T. Björkman, "Empowerment in people with a mental illness: reliability and validity of the Swedish version of an empowerment scale," Scandinavian Journal of Caring Sciences, vol. 19, no. 1, pp. 32-38, 2005.

[18] T. Kettunen, L. Liimatainen, J. Villberg, and U. Perko, "Developing empowering health counseling measurement. Preliminary results," Patient Education and Counseling, vol. 64, no. 1-3, pp. 159-166, 2006.

[19] E. S. Rogers, J. Chamberlin, M. L. Ellison, and T. Crean, "A consumer-constructed scale to measure empowerment among users of mental health services," Psychiatric Services, vol. 48, no. 8, pp. 1042-1047, 1997.

[20] S. Ferketich, "Focus on psychometrics: aspects of item analysis," Research in Nursing \& Health, vol. 14, no. 2, pp. 165-168, 1991.

[21] S. Uner and S. Turan, "The constructvalidity and reliability of the Turkish version of Spreitzer's psychological empowerment scale," BMC Public Health, vol. 10, article 117, 2010.

[22] K. Johansson, H. Lenino-Kilpi, S. Salanterä et al., "Need for change in patient education: a Finnish survey from the patient's perspective," Patient Education and Counseling, vol. 51, no. 3, pp. 239-245, 2003.

[23] K. A. Bollen, Structural Equation with Latent Variables, Wiley, New York, NY, USA, 1989.

[24] E. K. Kelloway, Using LISREL for Structural Equation Modeling: A Researcher's Guide, SAGE, Thousand Oaks, Calif, USA, 1998.

[25] K. G. Jöreskog and D. Sörbom, LISREL 8: Structural Equation Modeling with the SIMPLIS Command Language, Lawrence Erlbaum Associates Publishers, Hillsdale, NJ, USA, 1993.

[26] J. Ullman, "Structural equation modeling," in Using Multivariate Statistics, B. G. Tabachnick and L. S. Fidell, Eds., pp. 653-745, Allyn \& Bacon, Boston, Mass, USA, 4th edition, 2001.

[27] M. W. Browne and R. Cudeck, "Alternative ways of assessing model fit," in Testing Structural Equation Models, K. A. Bollen and J. S. Long, Eds., pp. 136-162, SAGE, Newbury Park, Calif, USA, 1993.

[28] R. B. Kline, Principals and Practice of Structural Equation Modeling, Guilford, New York, NY, USA, 1998.

[29] B. M. Byrne, Structural Equating Modeling with LISERL, PRELIS and SIMPLIS: Basic Concepts, Applications, and Programming, Lawrence Erlbaum Associates Publishers, Hillsdale, NJ, USA, 1998.

[30] J. C. Anderson and D. W. Gerbing, "Structural equation modeling in practice: a review and recommended two-step approach," Psychological Bulletin, vol. 103, no. 3, pp. 411-423, 1988.

[31] R. P. Bagozzi and Y. Yi, "On the evaluation of structural equation models," Journal of the Academy of Marketing Science, vol. 16, no. 1, pp. 74-94, 1988. 
[32] S. Piper, Health Promotion for Nurse: Theory and Practice, Routledge, London, UK, 2009.

[33] T. Kettunen, M. Poskiparta, and L. Liimatainen, "Empowering counseling-a case study: nurse-patient encounter in a hospital," Health Education Research, vol. 16, no. 2, pp. 227-238, 2001.

[34] G. W. Heiman, Research Methods in Psychology, Houghton Mifflin Company, Boston, Mass, USA, 3rd edition, 2002.

[35] D. Wild, A. Grove, M. Martin et al., "Principles of good practice for the translation and cultural adaptation process for PatientReported Outcomes (PRO) measures: report of the ISPOR Task Force for Translation and Cultural Adaptation," Value in Health, vol. 8, no. 2, pp. 94-104, 2005.

[36] D. E. Beaton, C. Bombardier, F. Guillemin, and M. B. Ferraz, "Guidelines for the process of cross-cultural adaptation of selfreport measures," Spine, vol. 25, no. 24, pp. 3186-3191, 2000.

[37] D. E. Irwin, J. W. Varni, K. Yeatts, and D. A. DeWalt, "Cognitive interviewing methodology in the development of a pediatric item bank: a patient reported outcomes measurement information system (PROMIS) study," Health and Quality of Life Outcomes, vol. 7, article 3, 2009. 


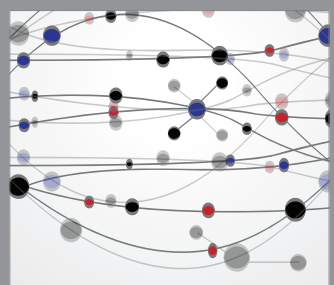

The Scientific World Journal
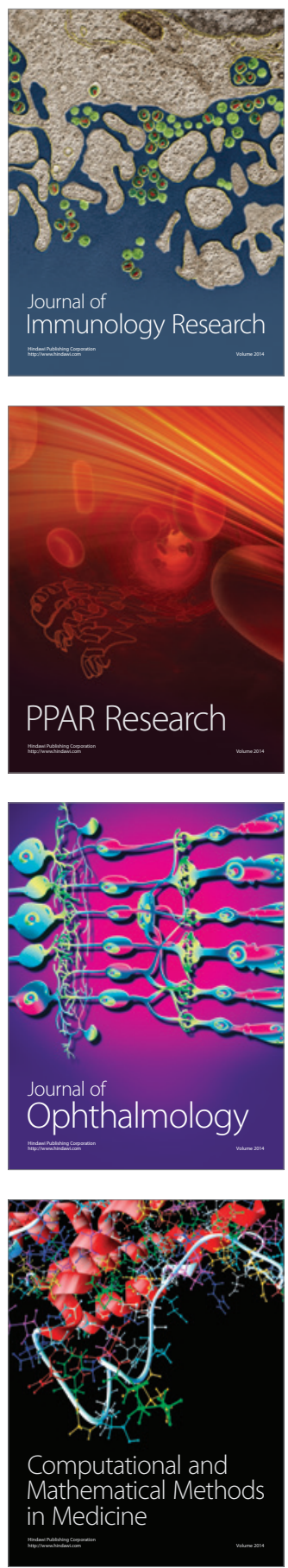

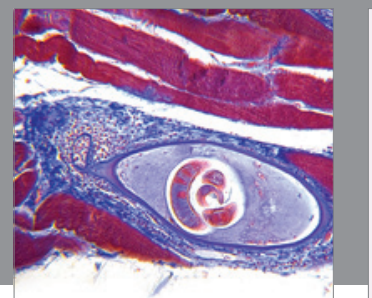

Gastroenterology

Research and Practice
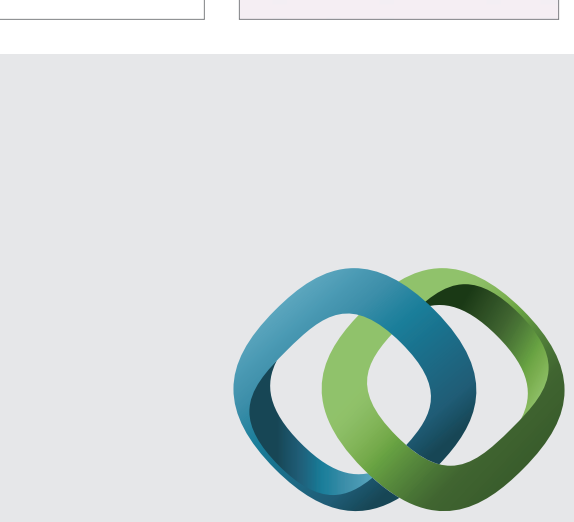

\section{Hindawi}

Submit your manuscripts at

http://www.hindawi.com
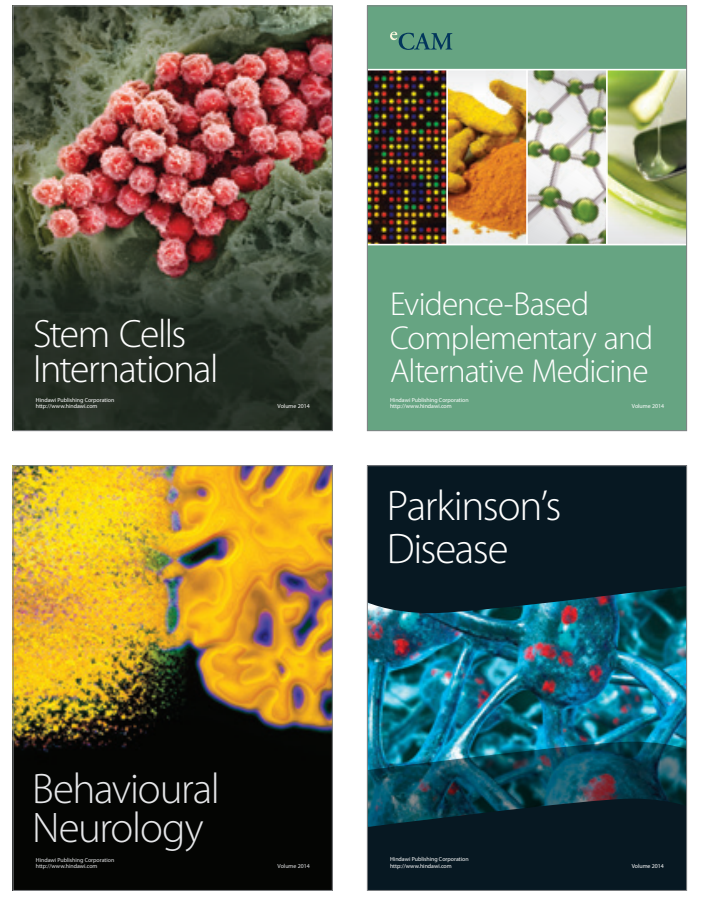
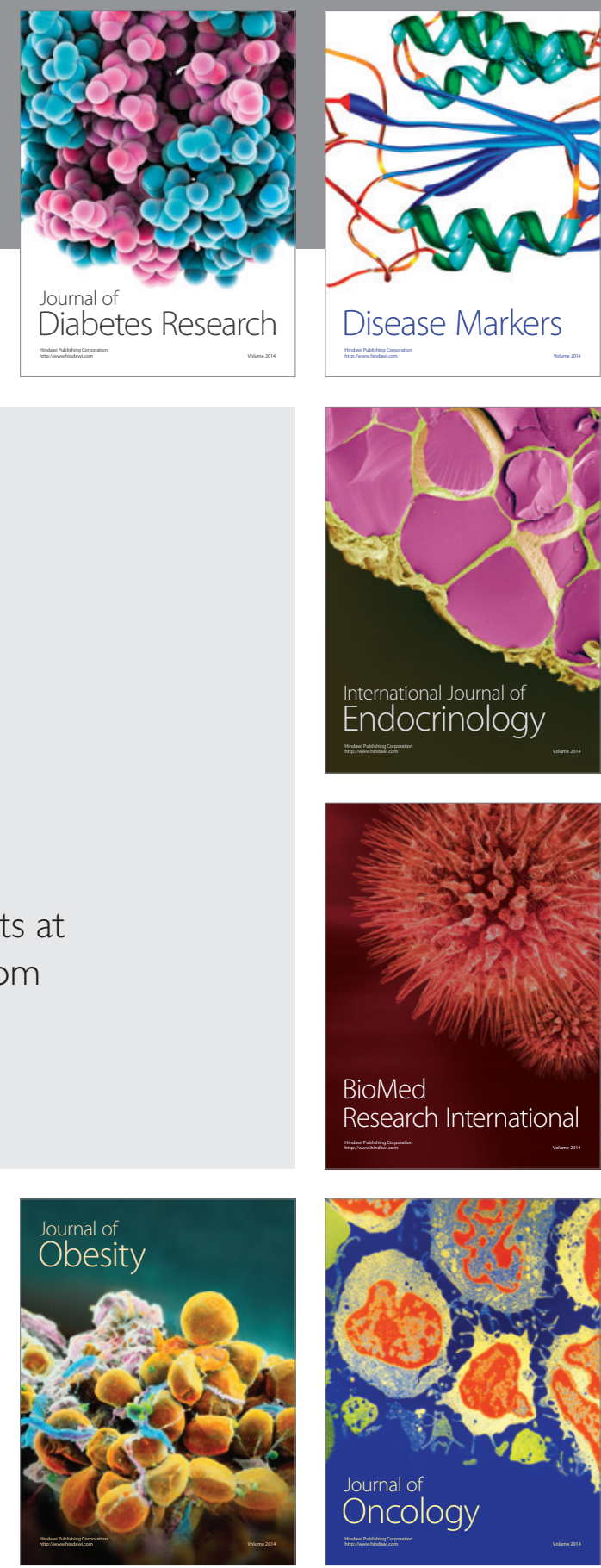

Disease Markers
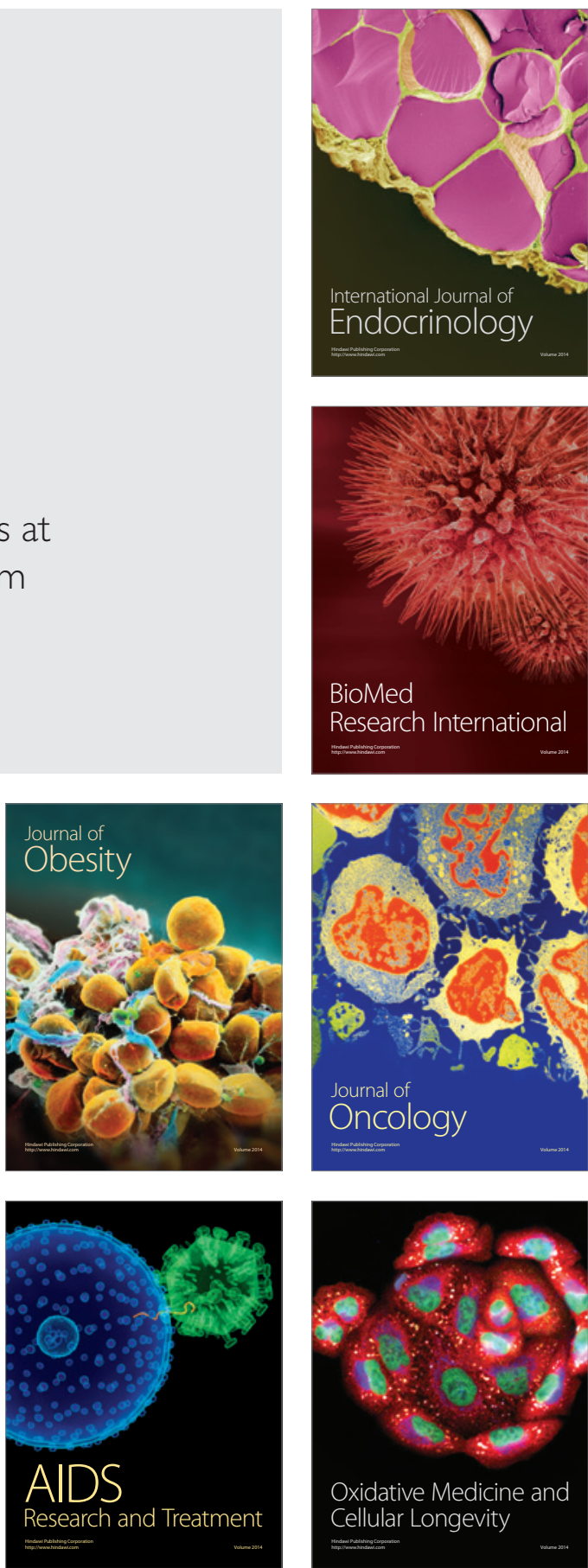